\title{
Efektivitas Konseling Behavioral Model Krumboltz untuk Mengembangkan Keputusan Karir Siswa
}

\author{
Wayan Udayani Sastrawati ${ }^{1}$, Ni Kadek Chandra Purwanti ${ }^{2}$, Kadek Suhardita ${ }^{3}$, \\ I Ketut Sapta ${ }^{4}$, Ni Komang Sri Yuliastini ${ }^{5}$ \\ SMK Negeri 1 Denpasar ${ }^{1,2}$, IKIP PGRI Bali ${ }^{3,4,5}$ \\ Email: udayani_anis@yahoo.com¹, nikdchandra@gmail.com², \\ kadeksuhardita8@gmail.com ${ }^{3}$, saptaketut@yahoo.com ${ }^{4}$, \\ komangyuli89@gmail.com ${ }^{5}$
}

\begin{abstract}
:
This research is an experimental study to cultivate student learning outcomes of grade XI Language of SMA N 1 Tabanan. Conditioning and user behavior are limited to those that can be used purely, can not be handled strictly. In this study, the control variables are Krumbotz counseling behavior, while the control class in this study is not given with the same as the experimental class. The sample of research, determined by random sampling technique is random sampling technique through drawing. Based on the First Hypothesis Testing the thitung value of -10.632 with $d f=(N-1)=(35-1)=34$ and $5 \%$ significance level then obtained the value of ttable of 2.032. Since it is larger than ttable, this proves that the first hypothesis in this study can be used and the behavior of the Krumboltz counselor is effective for making decisions for grade XI Language of SMA N 1 Tabanan. Based on Second Hypothesis Testing The average tcount of 8,739 with $d f=(N 1-1)+(N 2-1)=(35-1)+(35-1)=68$ and $5 \%$ significance level hence the obtained ttable value of 2.011. Since it is larger than ttable, it proves that there are two factors in this study that can be used to determine the behavior of the Krumbolt behavior model (experimental group) with groups of students who are not. Based on these results it will be done counseling behavior Krumboltz behavioral model to develop decisions that can be categorized well and can provide a very effective contribution.
\end{abstract}

Keyword: krumbotz counseling behavior, making decisions

Received February 11, 2019; Revised March 15, 2019; Accepted April 01, 2019

How to Cite: Sastrawati, W. U., Purwanti, N. K. C., Suhardita, K., Sapta I. K., \& Yuliastini, N. K. S. (2019). Efektivitas Konseling Behavioral Model Krumboltz untuk Mengembangkan Keputusan Karir Siswa. JKI (Jurnal Konseling Indonesia), 4(2), 63-67.

This is an open access article distributed under the Creative Commons 4.0 Attribution License, which permits unrestricted use, distribution, an reproduction in any medium, provided the original work is properly cited. @2019 by author and Universitas Kanjuruhan Malang.

\section{PENDAHULUAN}

Memilih jurusan merupakan awal bagi siswa untuk merencanakan karir demi masa depan (Adiputra, 2015). Sebagai siswa, mempunyai pandangan-pandangan yang berbeda terhadap tujuan karirnya sehingga cara untuk mewujudkan semua itu berbeda pula antara siswa satu dengan yang lainnya dalam memilih jurusan (Mardiyati \& Yuniawati, 2015). Banyak siswa masih cenderung terpengaruh oleh orang lain, tidak 
percaya diri, kurangnya pengetahuan tentang pekerjaan yang dinginkan, terpaku pada satu pilihan, tidak mampu mengenali bakat dan minatnya, tidak mendapat dukungan dari orang lain, tidak pasti dalam membuat pilihan, dan mengalami masalah berkenaan dengan pekerjaan yang diinginkan (Saputra \& Widiasari, 2017). Sebaliknya banyak siswa dalam memilih jurusan tidak lagi terpengaruh oleh orang lain, penuh percaya diri dalam membuat pilihan, sudah mempunyai pengetahuan tentang pekerjaan yang dinginkan, sudah mampu mengenali bakat dan minatnya, mendapat dukungan dari orang lain, yakin dalam membuat pilihan, dan tidak mengalami masalah berkenaan dengan pekerjaan yang diinginkan (Korohama et al., 2017). Hal-hal tersebut berkaitan dengan pengambilan keputusan karir siswa dimasa yang akan datang (Nurrega et al., 2018). Keputusan karir adalah perihal yang berkaitan dengan putusan yang telah ditetapkan sesudah melalui pertimbangan dan sudah dipikirkan sehingga memperoleh sikap terakhir (langkah yang harus dijalankan) (Islamadina \& Yulianti, 2017). Banyak siswa ketika menentukan keputusan karir mengalami keraguan, keprihatinan, ketidakpastian, keraguan pilihan dan ada juga yang mengalami kecemasan. Beberapa orang siswa mungkin benar-benar tidak tahu pekerjaan apa yang akan dipilihnya (Korohama et al., 2017). Ada juga siswa yang sudah mempunyai pilihan pasti namun masih ragu apakah pilihannya itu sudah sesuai dengan kemampuan dirinya (Setiobudi, 2017). Ada juga siswa yang sudah mantap pilihannya namun perlu mendapat dukungan dari orang yang sudah lebih berkompeten di bidang karirnya.

Berdasarkan aspek keputusan karir dan permasalahan di atas perlu kiranya siswa diberikan informasiinformasi melalui pelayanan bimbingan dan konseling. Teori pengambilan keputusan karir Behavioral dengan model (Krumboltz, 1979) yang mengemukakan bahwa cara seseorang membuat keputusan karir ditentukan oleh faktor-faktor pribadi dan lingkungan. Faktor pribadi berkenaan dengan apa yang sudah ada pada diri seseorang seperti jenis kelamin, rupa atau tampakan fisik dan kemampuan-kemampuan yang mengandung unsur bawaan. (Krumboltz, 1979) menyebutkan empat kategori faktor yang mempengaruhi pengambilan keputusan karir yaitu faktor genetik, lingkungan, belajar, dan keterampilan menghadapi tugas atau masalah. Menurut teori belajar, dalam pengambilan keputusan karir orang berada di lingkungan tertentu, dengan membawa ciri-ciri bawaan dari keturunannya dan menghadapi berbagai pengalaman belajar (Warsita, 2018). Orang memang tidak bisa mengatur sifat bawaannya, tetapi dapat mempengaruhi lingkungan dan pengalaman belajarnya. Teori belajar tentang keputusan karir, berguna untuk mengenali kondisi-kondisi lingkungan dan peristiwa yang memberikan pengalaman belajar kepada seseorang untuk menyusun rencana karir (Marti'ah et al., 2018).

Berdasarkan uraian tersebut di atas maka dapat disimpulkan bahwa konseling Behavioral model Krumboltz menjelaskan pengambilan keputusan karir menggunakan teori belajar sosial yang terdiri dari empat kategori faktor yang mempengaruhi pengambilan keputusan karir yaitu faktor genetik, lingkungan, belajar, dan keterampilan menghadapi tugas atau masalah sehingga dalam membuat keputusan karir dapat diperbaiki dengan mengubah bentuk proses belajar.

\section{METODE PENELITIAN}

Penelitian ini merupakan studi eksperimen untuk mengembangkan keputusan karir siswa kelas XI Bahasa SMA N 1 Tabanan. Pengkondisian dan perilaku siswa hanya sebatas yang dapat dikontrol secara kuasi dan menghindari kontrol yang murni, sehingga kontrol terhadap perilaku siswa tidak terlalu ketat. Penelitian ini bertujuan untuk mengetahui keefektifan konseling behavioral model Krumboltz untuk mengembangkan keputusan karir pada siswa melibatkan pengaruh variabel bebas terhadap variabel terikat yang desainnya "Pre-Posttest Control Group Design".

Penelitian ini menggunakan subjek siswa kelas XI Bahasa SMA N 1 Tabanan, Kecamatan Pupuan, Kabupaten Tabanan. Sampel penelitian, peneliti tentukan dengan teknik random sampling yaitu teknik mengambil sampel secara acak melalui pengundian. Berdasarkan hasil random kelas yag munculsebagai perwakilan yaitu merandom dua kelas yang diperoleh pada tahap pertama untuk menentukan kelas eksperimen dan kelas kontrol. Dari teknik random yang kedua diperoleh kelas X IPA1 sebagai kelas eksperimen dan X IPS1 sebagai kelas kontrol.

Metode analisis data yang digunakan dalam penelitian ini dilakukan dalam beberapa tahap yaitu 1) Uji prasyarat statistik. Data yang akan dianalisis harus memenuhi uji prasyarat statistik yaitu a) Uji normalitas sebaran data yang akan dianalisis dengan Kolmogorov-Smirnov pada program SPSS 16.0. for Windows dan b) Uji homogenitas yang akan dianalisis dengan uji Leven's pada program SPSS 16.0. for Windows. dan 2) Uji hipotesis. Analisis data dalam penelitian ini dijabarkan dalam dua hipotesis yang akan dianalisis dengan t-test. Untuk menguji hipotesis pertama digunakan analisis statistik Paired Sampel T-test. Dalam analisis uji hipotesis pertama yang dijadikan perhitungan adalah pretest kelompok eksperimen dan posttest kelompok eksperimen. Untuk menguji hipotesis kedua digunakan statistik Independent Sampel T-test. 


\section{Jurnal Konseling Indonesia}

http://ejournal.unikama.ac.id/index.php/JKI

ISSN: Print 2475-888X - Online 2476-8901

\section{HASIL}

Analisis data dalam penelitian ini termasuk analisis data kuantitatif. Untuk memudahkan perhitungan uji hipotesis dibantu dengan program SPSS 16.0 for Windows. Rumusan hipotesis pertama pada penelitian ini yaitu, bimbingan konseling behavioral model Krumboltz efektif untuk mengembangkan keputusan karir pada siswa kelas XI Bahasa SMA N 1 Tabanan. Untuk melakukan uji hipotesis ini digunakan perhitungan pretest kelompok eksperimen dengan posttest kelompok eksperimen sehingga didapat hasil pada tabel 1 sebagai berikut.

Tabel 1. Rerata pretest kelompok eksperimen dan posttest kelompok eksperiemen

\begin{tabular}{|l|l|l|r|r|r|}
\hline & & Mean & \multicolumn{1}{c|}{$\mathrm{N}$} & \multicolumn{1}{c|}{ Std. Deviation } & \multicolumn{1}{c|}{$\begin{array}{c}\text { Std. Error } \\
\text { Mean }\end{array}$} \\
\hline Pair 1 & Pretest Kel Eksperimen & 254.14286 & 35 & 19.854090 & 3.355954 \\
\cline { 2 - 6 } & Posttest Kel Eksperimen & 282.20000 & 35 & 12.399715 & 2.095934 \\
\hline
\end{tabular}

Berdasarkan tabel di atas, rata-rata posttest kelompok eksperimen lebih tinggi daripada pretest kelompok eksperimen. Maka bimbingan konseling behavioral model Krumboltz dapat meningkatkan keputusan karir siswa.

Tabel 2. Hasil analisis data keputusan karir dari perbedaan pretest kelompok eksperimen dan posttest kelompok eksperimen

\begin{tabular}{|c|c|c|c|c|c|c|c|c|c|}
\hline & \multicolumn{5}{|c|}{ Paired Differences } & \multirow[b]{3}{*}{$\mathrm{t}$} & \multirow[b]{3}{*}{ df } & \multirow{3}{*}{$\begin{array}{l}\text { Sig. } \\
(2- \\
\text { taile } \\
\text { d) }\end{array}$} \\
\hline & & \multirow[b]{2}{*}{ Mean } & \multirow{2}{*}{$\begin{array}{c}\text { Std. } \\
\text { Deviation }\end{array}$} & \multirow{2}{*}{$\begin{array}{l}\text { Std. Error } \\
\text { Mean }\end{array}$} & \multicolumn{2}{|c|}{$\begin{array}{l}95 \% \text { Confidence Interval } \\
\text { of the Difference }\end{array}$} & & & \\
\hline & & & & & Lower & Upper & & & \\
\hline Pair 1 & $\begin{array}{l}\text { Pretest Kel } \\
\text { Elksperimen - } \\
\text { Posttest Kel } \\
\text { Elssperimen }\end{array}$ & -28.057143 & 15.612858 & 2.639055 & -33.420347 & -22.693938 & -10.632 & 34 & .000 \\
\hline
\end{tabular}

Berdasarkan nilai t pada tabel 2 diatas maka diperoleh $t_{\text {hitung }}$ sebesar -10,632 dengan df $=(\mathrm{N}-1)=(35$ $1)=34$ dan taraf signifikansi $5 \%$ maka diperoleh nilai $t_{\text {tabel }}$ sebesar 2,032. Karena $t_{\text {hitung }}$ lebih besar dari $t_{\text {tabel }}$, ini membuktikan bahwa hipotesis pertama dalam penelitian ini dapat diterima dan berarti bimbingan konseling behavioral model Krumboltz efektif untuk mengembangkan keputusan karir siswa kelas XI Bahasa SMA N 1 Tabanan

Rumusan hipotesis kedua pada penelitian ini yaitu, terdapat perbedaan keputusan karir siswa antara kelompok siswa yang diberikan bimbingan konseling behavioral model Krumboltz (kelompok eksperimen) dengan kelompok siswa yang tidak diberikan bimbingan konseling behavioral model Krumboltz (kelompok kontrol).

Untuk melakukan uji hipotesis kedua digunakan perhitungan data keputusan karir antara gain score kelompok eksperimen dengan data keputusan karir gain score kelompok kontrol, sehingga didapat hasil pada tabel 3 sebagai berikut.

Tabel 3. Rerata gain score kelompok eksperimen dan gain score kelompok kontrol

\begin{tabular}{|c|c|c|c|c|c|}
\hline & & $\mathrm{N}$ & Mean & Std. Deviation & Std. Error Mean \\
\hline $\begin{array}{c}\text { Gain score kel eksperimen } \\
\text { dan control }\end{array}$ & 1 & 35 & 28.0571 & 15.61286 & 2.63905 \\
\cline { 2 - 6 } & 2 & 35 & 3.8571 & 4.62183 & .78123 \\
\hline
\end{tabular}

Dalam tabel 3 di atas, rata-rata gain score kelompok eksperimen lebih tinggi daripada gain score kelompok kontrol. Maka bimbingan konseling behavioral model Krumboltz dapat mengembangkan keputusan karir siswa. 
Tabel 4. Hasil analisis data keputusan karir dari perbedaan gain score kelompok ksperimen dengan gain score kelompok kontrol

\begin{tabular}{|c|c|c|c|c|c|c|c|c|c|c|}
\hline & \multicolumn{2}{|c|}{$\begin{array}{l}\text { Leyene's } \\
\text { Test for } \\
\text { Equality of } \\
\text { Variances }\end{array}$} & \multicolumn{7}{|c|}{ t-test for Equality of Means } \\
\hline & & & & \multirow[b]{2}{*}{$\mathrm{T}$} & \multirow[b]{2}{*}{$\mathrm{Df}$} & \multirow{2}{*}{$\begin{array}{l}\text { Sig. } \\
(2- \\
\text { taile } \\
\text { d) }\end{array}$} & \multirow[b]{2}{*}{ Mean Dif } & \multirow{2}{*}{$\begin{array}{l}\text { Std. } \\
\text { Error } \\
\text { Dif }\end{array}$} & \multicolumn{2}{|c|}{$\begin{array}{c}95 \% \text { Confidence } \\
\text { Interval of the } \\
\text { Difference }\end{array}$} \\
\hline & & $\mathrm{F}$ & Sig. & & & & & & Lower & Upper \\
\hline \multirow{2}{*}{$\begin{array}{l}\text { Gain score } \\
\text { kel } \\
\text { eksperimen } \\
\text { dan control }\end{array}$} & \begin{tabular}{|l|} 
Equal \\
variances \\
assumed
\end{tabular} & 27.453 & .000 & 8.793 & 68 & .000 & 24.20000 & 2.75226 & 18.70795 & 29.69205 \\
\hline & \begin{tabular}{|l|} 
Equal \\
variances \\
not \\
assumed
\end{tabular} & & & 8.793 & 39.914 & .000 & 24.20000 & 2.75226 & 18.63710 & 29.76290 \\
\hline
\end{tabular}

Berdasarkan nilai t pada tabel 4 diatas maka diperoleh $t_{\text {hitung }}$ sebesar 8,739 dengan df $=\left(\mathrm{N}_{1}-1\right)+\left(\mathrm{N}_{2}-1\right)=$ $(35-1)+(35-1)=68$ dan taraf signifikansi 5\% maka diperoleh nilai $t_{\text {tabel }}$ sebesar 2,011. Karena $t_{\text {hitung }}$ lebih besar dari $t_{\text {tabel, }}$ ini membuktikan bahwa hipotesis kedua dalam penelitian ini dapat diterima dan berarti terdapat perbedaan keputusan karir siswa antara kelompok siswa yang diberikan bimbingan konseling behavioral model Krumboltz (kelompok eksperimen) dengan kelompok siswa yang tidak diberikan bimbingan konseling behavioral model Krumboltz (kelompok kontrol).

\section{PEMBAHASAN}

Berdasarkan hasil pengujian hipotesis yang telah disajikan di atas dapat disampaikan beberapa pembahasan berkenaan dengan penelitian ini. Sesuai dengan hasil pengujian hipotesis pertama yang diperoleh dengan membandingkan pretest kelompok eksperimen dan pretest kelompok eksperimen maka hipotesis pertama yang diajukan dalam penelitian ini dapat diterima. Dengan diterimanya hipotesis pertama menunjukkan bahwa bimbingan konseling behavioral model Krumboltz efektif untuk mengembangkan keputusan karir pada siswa XI Bahasa SMA N 1 Tabanan. Dengan diberikannya konseling behavioral model Krumboltz siswa bisa mengambil keputusan karir dengan mengikuti langkah-langkah pengambilan keputusan karir yaitu mengumpulkan informasi tentang karir, mempertimbangkan, memilih, merencanakan, dan melaksanakan pilihan. Kenyataan di lapangan menunjukkan bahwa masih banyak siswa mengalami masalah berkenaan dengan keputusan karir sehingga perlu mendapat pelayanan yang lebih baik melalui proses konseling.

Dalam pelaksanaan kegiatan, peneliti mengajak siswa yang mengalami masalah berkenaan dengan karir untuk mengikuti konseling. Konseling ini dilakukan berdasarkan hasil diagnosa selama berlangsungnya kegiatan. Siswa yang diidentifikasi mengalami masalah maka selanjutnya diajak untuk mengikuti konseling.

Hal lain yang diperoleh dari hasil analisis data pada penelitian ini menunjukkan bahwa sesuai dengan hasil pengujian hipotesis kedua yang diperoleh dengan membandingkan antara gain score kelompok eksperimen dengan gain score kelompok kontrol maka hipotesis kedua yang diajukan dalam penelitian ini dapat diterima. Dengan diterimanya hipotesis kedua menunjukkan bahwa terdapat perbedaan keputusan karir siswa antara kelompok siswa yang diberikan konseling behavioral model Krumboltz (kelompok eksperimen) dengan kelompok siswa yang tidak diberikan konseling behavioral model Krumboltz (kelompok kontrol).

Berdasarkan hasil tersebut maka secara menyeluruh pelaksanaan kegiatan konseling behavioral model Krumboltz untuk mengembangkan keputusan karir dapat dikategorikan baik dan dapat memberikan sumbangan yang sangat efektif. 


\section{SIMPULAN DAN SARAN}

Berdasarkan hasil analisis di atas dapat disimpulkan bahwa Bimbingan konseling behavioral model Krumboltz efektif untuk mengembangkan keputusan karir pada siswa. Terdapat perbedaan keputusan karir siswa antara kelompok siswa yang diberikan bimbingan konseling behavioral model Krumboltz (kelompok eksperimen) dengan kelompok siswa yang tidak diberikan bimbingan konseling behavioral model Krumboltz (kelompok kontrol).

Berdasarkan hasil penelitian sebagaimana disimpulkan di atas dapat dikemukakan beberapa saran. Yaitu disarankan kepada instansi/ sekolah/ guru agar lebih meningkatkan pelayanan bidang bimbingan karir kepada siswa, dengan cara memanfaatkan bimbingan konseling. Kepada semua siswa SMA Negeri 1 Tabanan disarankan agar dapat mengikuti bimbingan konseling behavioral model Krumboltz untuk mengembangkan keputusan karir siswa.

\section{DAFTAR RUJUKAN}

Adiputra, S. (2015). Penggunaan Teknik Modeling Terhadap Perencanaan Karir Siswa. Jurnal Fokus Konseling, 1(1), 45-56.

Islamadina, E. F., \& Yulianti, A. (2017). Persepsi terhadap dukungan orangtua dan kesulitan pengambilan keputusan karir pada remaja. Jurnal Psikologi, 12(1), 33-38.

Korohama, K. E. P., Wibowo, M. E., \& Tadjri, I. (2017). Model Bimbingan Kelompok dengan Teknik Modeling untuk Meningkatkan Kematangan Karir Siswa. Jurnal Bimbingan Konseling, 6(1), 68-76.

Krumboltz, J. D. (1979). A social learning theory of career decision making. Social Learning and Career Decision Making, 19-49.

Mardiyati, B. D., \& Yuniawati, R. (2015). Perbedaan adaptabilitas karir ditinjau dari jenis sekolah (SMA dan SMK). Empathy, 3(1), 31-41.

Marti'ah, S., Theodora, B. D., \& Haryanto, H. (2018). Pengaruh Lingkungan Keluarga terhadap Pilihan Karir Siswa. SAP (Susunan Artikel Pendidikan), 2(3).

Nurrega, R. G., Wahyuningsih, H., \& Gusniarti, U. (2018). Konseling Karir Kelompok Cognitive Information Processing untuk Meningkatkan Pengambilan Keputusan Karir Siswa. Journal of Psychological Science and Profession, 2(1), 127-134.

Saputra, W. N. E., \& Widiasari, S. (2017). Konseling Karir Ringkas Berfokus Solusi: Konseling Karir Untuk Membantu Menetapkan Pilihan Karir Siswa Smk Menghadapi Mea. Jurnal Fokus Konseling, 3(1), 24 31.

Setiobudi, J. (2017). Pengaruh efikasi diri terhadap pengambilan keputusan karir pada siswa kelas xii sma negeri 1 kalasan. Jurnal Riset Mahasiswa Bimbingan Dan Konseling, 3(1), 98-111.

Warsita, B. (2018). Teori Belajar Robert M. Gagne dan Implikasinya pada Pentingnya Pusat Sumber Belajar. Jurnal Teknodik, 12(1), 64-78. 